\title{
Article \\ Favorable Lip and Oral Cancer Mortality-to-Incidence Ratios in Countries with High Human Development Index and Expenditures on Health
}

\author{
Wen-Wei Sung $1,2,3,+\oplus$, Yong-Chen Hsu ${ }^{4,+} \oplus$, Chen Dong ${ }^{2} \oplus$, Ying-Ching Chen ${ }^{2}$, Yu-Chi Chao ${ }^{2}$ \\ and Chih-Jung Chen $2,4, * \mathbb{B}$ \\ 1 Department of Urology, Chung Shan Medical University Hospital, Taichung 40201, Taiwan; \\ flutewayne@gmail.com \\ 2 School of Medicine, Chung Shan Medical University, Taichung 40201, Taiwan; \\ s0901047@gm.csmu.edu.tw (C.D.); ma611821@gmail.com (Y.-C.C.); c928714@gmail.com (Y.-C.C.) \\ 3 Institute of Medicine, Chung Shan Medical University, Taichung 40201, Taiwan \\ 4 Department of Pathology and Laboratory Medicine, Taichung Veterans General Hospital, \\ Taichung 40201, Taiwan; shuyongjen@hotmail.com \\ * Correspondence: cjchen1016@gmail.com; Tel.: +886-4-2359-2525 \\ + Wen-Wei Sung and Yong-Chen Hsu contributed equally to this manuscript.
}

\section{check for}

updates

Citation: Sung, W.-W.; Hsu, Y.-C.; Dong, C.; Chen, Y.-C.; Chao, Y.-C.; Chen, C.-J. Favorable Lip and Oral Cancer Mortality-to-Incidence Ratios in Countries with High Human Development Index and Expenditures on Health. Int. J. Environ. Res. Public Health 2021, 18, 6012. https://doi.org/10.3390/ ijerph18116012

Academic Editor: Paul B. Tchounwou

Received: 17 May 2021

Accepted: 2 June 2021

Published: 3 June 2021

Publisher's Note: MDPI stays neutral with regard to jurisdictional claims in published maps and institutional affiliations.

Copyright: (c) 2021 by the authors. Licensee MDPI, Basel, Switzerland. This article is an open access article distributed under the terms and conditions of the Creative Commons Attribution (CC BY) license (https:/ / creativecommons.org/licenses/by/ $4.0 /)$.
Abstract: Background: The incidence rates of lip and oral cancer have continued to increase, and prognosis is associated with a country's socioeconomic status. The mortality-to-incidence ratio (MIR) is a reasonable indicator of disparities in cancer screening and treatment. In this study, we aimed to understand the association between economic status and cancer prognosis. Methods: Data were obtained from the Global Cancer Observatory (GLOBOCAN) and the World Health Organization (WHO). The MIRs were compared to evaluate the correlation with the human development index (HDI), the current health expenditure (CHE), and the ratio of $\mathrm{CHE}$ over gross domestic product (CHE/GDP) disparities via Spearman's rank correlation coefficient. Results: The results showed that Asia had the most cases and deaths. In addition, they showed a significant association $(p<0.001$, $p=0.005$, and $p<0.001$, respectively) of the crude rate (CR) of incidence with the HDI, the CHE, and the CHE/GDP. However, their associations with mortality rate $(p=0.303, p=0.997$, and $p=0.101)$ were not significant. Regarding the correlation of the MIRs, the results revealed a significant association with the HDI, the CHE, and the CHE/GDP $(p<0.001, p<0.001$, and $p<0.001$, respectively). Conclusion: Countries with higher HDI, CHE per capita, and CHE/GDP tend to have lower MIRs, which indicates favorable clinical outcomes.

Keywords: lip and oral cancer; mortality; incidence; mortality-to-incidence ratio; expenditure; human development index

\section{Introduction}

Lip and oral cancers are among the most common cancers worldwide, and their incidence rates have continuously increased in recent years [1]. Although they vary geographically, the highest incidences have been reported in South Asia and Southeast Asia [2]. Among all anatomic subsites of lip and oral cavity cancer, the tongue is the most commonly affected worldwide. The second most commonly affected site in Asia is the buccal/labial mucosa [3]. Common risk factors for lip and oral cavity cancer include tobacco, alcohol, betel quid, Epstein-Barr virus, and human papillomavirus infection [4,5]. Oral cavity cancer with leukoplakia can be diagnosed in early stages by visual examination, biopsy, or image study. Thus, early oral screening is crucial to ensure a five-year survival rate [6,7]. However, poor and less educated people with risk factors seldom obtain screening for oral cancer, and diagnosis is usually delayed [8]. 
Standard treatment varies according to the stage of oral cancer, including surgical resection, radiotherapy, chemotherapy, or their combination [9]. A previous study indicated that during the past 40 years, the prognosis of oral cancer has substantially improved, which has been due to the application of adjuvant radiotherapy, targeting therapy, and adjuvant chemoradiotherapy [10,11]. Recently, immunotherapy has emerged as a potential and effective treatment $[9,12]$. The prognosis of oral cancer is related to several factors, such as race [13], anatomic subsites [14], and diagnosed stage. Prognosis varies with disparities in socioeconomic status [15]. People with limited income and heavier oral cancer disease burden may receive less definitive therapy and have lower overall survival rates than others $[16,17]$. As the early detection of oral cancer is one of the most important factors that affect overall survival and prognosis [18], an affordable oral cancer examination could help early diagnosis, improve prognosis, and increase survival rates [19].

The mortality-to-incidence ratio (MIR) is calculated by crude mortality rates over crude incidence rates, which determines whether a country has a higher or lower mortality rate [20] and reveals the overall mortality rate after diagnosis of the disease [21]. Sunkara and Hébert's study [22] suggested that the MIR could be a useful indicator for identifying regional disparities in cancer screening and treatment.

As the MIR indicates mortality after accounting for incidence, it can help in assessing the prognosis of cancer and its burden on healthcare. Thus, in this study, we evaluate health expenditures, the human development index (HDI), and the MIRs of selected countries to understand the association between economic status and cancer prognosis.

\section{Materials and Methods}

Epidemiological data on lip and oral cavity cancer, ICD-10 C00-06, were obtained from the Global Cancer Observatory (GLOBOCAN) database (https:/ /gco.iarc.fr/today/, accessed date: 11 October 2020), which is a public access database that provides contemporary estimates of cancer epidemiology in 185 countries for 2018. The HDI was obtained from the United Nations Development Program, Human Development Report Office (http://hdr.undp.org/en, accessed date: 11 October 2020). Health expenditure data, including the per capita current health expenditure (CHE) and the ratio of CHE to gross domestic product (CHE/GDP), were obtained from the World Health Statistics database (https://www.who.int/gho/publications/world_health_statistics/en/, accessed date: 11 October 2020).

The MIR is defined as the ratio of the crude rate (CR) of mortality to the CR of incidence, as previously described [22-25]. The exclusion criteria for country selection were based on missing data in the World Health Organization (WHO) statistics $(\mathrm{N}=12)$, missing data of the HDI $(\mathrm{N}=2)$, and the data quality report by the GLOBOCAN $(\mathrm{N}=110)$ [26]. A total of 61 countries were included in the analysis. The associations between the MIR and the HDI, the CHE, and the CHE/GDP in various countries were estimated using Spearman's rank correlation coefficient, which was calculated using SPSS statistical software version 15.0 (SPSS, Inc., Chicago, IL, USA). Values of $p<0.05$ were considered statistically significant. Scatterplots were generated using SigmaPlot.

\section{Results}

\subsection{Epidemiology of Lip and Oral Cancer According to the Regions}

We surveyed 339,913 new cases and 168,169 deaths from lip and oral cavity cancer in this study. The selected countries are grouped into six regions based on the continent in which they were located. The incidence and mortality case numbers, CR, age standardized rate (ASR), and MIR are presented in Table 1. The findings showed the incidence numbers in Africa (13,324), Asia $(220,810)$, Europe $(57,737)$, Latin America and the Caribbean $(18,525)$, North America $(25,354)$, and Oceania $(4163)$. The findings also showed the number of deaths in Africa (9066), Asia (124,900), Europe (21,834), Latin America and the Caribbean (7050), North America (4424), and Oceania (895). Among all the selected regions, Asia was 
shown to have the highest numbers of cases and deaths, while Oceania had the lowest numbers of cases and deaths.

Table 1. Summary of the number, crude rank, ASR, and MIR of lip and oral cancer by region.

\begin{tabular}{cccccccc}
\hline & \multicolumn{3}{c}{ New Cases } & \multicolumn{3}{c}{ Deaths } & \multirow{2}{*}{ MIR } \\
\cline { 1 - 6 } Region & Number & CR & ASR & Number & CR & ASR & \\
\hline Africa & 13,324 & 1.0 & 1.7 & 9066 & 0.7 & 1.2 & 0.71 \\
Asia & 220,810 & 4.9 & 4.2 & 124,900 & 2.8 & 2.4 & 0.57 \\
Europe & 57,737 & 8.0 & 4.3 & 21,834 & 3.0 & 1.6 & 0.38 \\
Latin America and the & 18,525 & 2.9 & 2.6 & 7050 & 1.1 & 1.0 & 0.38 \\
Caribbean & 25,354 & 7.1 & 4.2 & 4424 & 1.2 & 0.7 & 0.17 \\
North America & 4163 & 10.2 & 7.5 & 895 & 2.2 & 1.5 & 0.22 \\
Oceania & & & & & & &
\end{tabular}

3.2. Epidemiology and Parameters of the Development and Health Expenditure of Lip and Oral Cancer in the Selected Countries

The HDI, CHE, cancer incidence, cancer mortality, and MIR of selected countries are shown in Table 2. Egypt had the lowest HDI (0.700), and Norway had the highest HDI (0.954). The CHE/GDP ranges from 3.1\% (Qatar) to 16.8\% (USA). The incidence crude rates in all the examined countries ranged from 1.0 in Qatar and Bahrain to 12.7 in Latvia. The age standardized incidence rate (ASR) ranged from 1.1 in Chile to 6.9 in Australia. Egypt had the lowest mortality CR (0.4), and Latvia had the highest mortality CR (6.0). Chile, Egypt, Israel, Malta, and Jamaica had the lowest age standardized mortality rate (ASMR, 0.4), and Latvia had the highest ASMR (3.2). The MIR ranged from 0.14 in Australia to 0.64 in Bahrain.

Table 2. Summary of HDI, CHE, cancer incidence, cancer mortality, and MIR in lip and oral cancer $(\mathrm{N}=61)$.

\begin{tabular}{|c|c|c|c|c|c|c|c|c|c|c|}
\hline \multirow[b]{2}{*}{ Country } & \multirow[b]{2}{*}{ HDI } & \multicolumn{2}{|c|}{$\mathrm{CHE}$} & \multicolumn{3}{|c|}{ Incidence } & \multicolumn{3}{|c|}{ Mortality } & \multirow[b]{2}{*}{ MIR } \\
\hline & & $\begin{array}{c}\text { Per } \\
\text { Capita }\end{array}$ & $\begin{array}{l}\% \text { of } \\
\text { GDP }\end{array}$ & Number & $\mathrm{CR}$ & ASR & Number & CR & ASR & \\
\hline Argentina & 0.830 & 998 & 6.8 & 1357 & 3.1 & 2.5 & 512 & 1.2 & 0.9 & 0.39 \\
\hline Australia & 0.938 & 4934 & 9.4 & 2682 & 11.1 & 6.9 & 378 & 1.6 & 0.9 & 0.14 \\
\hline Austria & 0.914 & 4536 & 10.3 & 488 & 5.7 & 3.0 & 232 & 2.7 & 1.4 & 0.47 \\
\hline Bahrain & 0.838 & 1190 & 5.2 & 16 & 1.0 & 1.5 & 10 & 0.6 & 1.0 & 0.64 \\
\hline Belarus & 0.817 & 352 & 6.1 & 653 & 7.0 & 4.1 & 316 & 3.4 & 2.0 & 0.49 \\
\hline Belgium & 0.919 & 4228 & 10.5 & 923 & 8.3 & 4.7 & 305 & 2.7 & 1.4 & 0.33 \\
\hline Brazil & 0.761 & 780 & 8.9 & 9902 & 4.7 & 4.0 & 3965 & 1.9 & 1.6 & 0.40 \\
\hline Bulgaria & 0.816 & 572 & 8.2 & 459 & 6.7 & 3.4 & 164 & 2.4 & 1.2 & 0.36 \\
\hline Canada & 0.922 & 4508 & 10.4 & 2633 & 7.3 & 3.9 & 594 & 1.6 & 0.8 & 0.22 \\
\hline Chile & 0.847 & 1102 & 8.1 & 275 & 1.5 & 1.1 & 113 & 0.6 & 0.4 & 0.42 \\
\hline Colombia & 0.761 & 374 & 6.2 & 775 & 1.6 & 1.4 & 308 & 0.6 & 0.5 & 0.39 \\
\hline Costa Rica & 0.794 & 929 & 8.1 & 78 & 1.6 & 1.2 & 35 & 0.7 & 0.5 & 0.44 \\
\hline Croatia & 0.837 & 852 & 7.4 & 291 & 7.2 & 3.8 & 117 & 2.9 & 1.5 & 0.40 \\
\hline Cuba & 0.778 & 826 & 10.9 & 1238 & 11.0 & 6.2 & 380 & 3.4 & 1.8 & 0.31 \\
\hline Cyprus & 0.873 & 1563 & 6.8 & 29 & 2.5 & 1.6 & 8 & 0.7 & 0.5 & 0.27 \\
\hline Czechia & 0.891 & 1284 & 7.3 & 859 & 8.3 & 4.3 & 361 & 3.5 & 1.8 & 0.42 \\
\hline Denmark & 0.930 & 5497 & 10.3 & 397 & 7.1 & 3.8 & 125 & 2.2 & 1.1 & 0.31 \\
\hline Ecuador & 0.758 & 530 & 8.5 & 217 & 1.3 & 1.2 & 82 & 0.5 & 0.5 & 0.38 \\
\hline Egypt & 0.700 & 157 & 4.2 & 1295 & 1.3 & 1.6 & 352 & 0.4 & 0.4 & 0.28 \\
\hline Estonia & 0.882 & 1112 & 6.5 & 79 & 6.2 & 3.3 & 40 & 3.1 & 1.7 & 0.50 \\
\hline Fiji & 0.724 & 175 & 3.6 & 27 & 3.0 & 2.9 & 11 & 1.2 & 1.2 & 0.40 \\
\hline Finland & 0.925 & 4005 & 9.4 & 348 & 6.5 & 3.0 & 116 & 2.2 & 0.9 & 0.34 \\
\hline France & 0.891 & 4026 & 11.1 & 6815 & 10.8 & 6.2 & 1516 & 2.4 & 1.3 & 0.22 \\
\hline Germany & 0.939 & 4592 & 11.2 & 7271 & 9.1 & 4.4 & 2311 & 2.9 & 1.3 & 0.32 \\
\hline
\end{tabular}


Table 2. Cont.

\begin{tabular}{|c|c|c|c|c|c|c|c|c|c|c|}
\hline \multirow[b]{2}{*}{ Country } & \multirow[b]{2}{*}{ HDI } & \multicolumn{2}{|c|}{ CHE } & \multicolumn{3}{|c|}{ Incidence } & \multicolumn{3}{|c|}{ Mortality } & \multirow[b]{2}{*}{ MIR } \\
\hline & & $\begin{array}{c}\text { Per } \\
\text { Capita }\end{array}$ & $\begin{array}{l}\% \text { of } \\
\text { GDP }\end{array}$ & Number & CR & ASR & Number & CR & ASR & \\
\hline Iceland & 0.938 & 4375 & 8.6 & 13 & 3.9 & 2.3 & 3 & 0.9 & 0.5 & 0.23 \\
\hline Ireland & 0.942 & 4757 & 7.8 & 275 & 5.8 & 3.7 & 74 & 1.6 & 0.9 & 0.28 \\
\hline Israel & 0.906 & 2756 & 7.4 & 155 & 1.9 & 1.4 & 51 & 0.6 & 0.4 & 0.32 \\
\hline Italy & 0.883 & 2700 & 9.0 & 3500 & 6.1 & 2.7 & 1184 & 2.1 & 0.9 & 0.34 \\
\hline Jamaica & 0.726 & 294 & 5.9 & 52 & 1.8 & 1.5 & 15 & 0.5 & 0.4 & 0.29 \\
\hline Japan & 0.915 & 3733 & 10.9 & 8138 & 6.7 & 2.8 & 2496 & 2.1 & 0.7 & 0.31 \\
\hline Kuwait & 0.808 & 1169 & 4.0 & 59 & 1.4 & 2.0 & 33 & 0.8 & 1.1 & 0.56 \\
\hline Latvia & 0.854 & 784 & 5.8 & 239 & 12.7 & 6.8 & 113 & 6.0 & 3.2 & 0.47 \\
\hline Lithuania & 0.869 & 923 & 6.5 & 188 & 6.7 & 3.7 & 114 & 4.1 & 2.3 & 0.61 \\
\hline Luxembourg & 0.909 & 6236 & 6.0 & 45 & 7.8 & 4.8 & 10 & 1.7 & 1.0 & 0.22 \\
\hline Malaysia & 0.804 & 386 & 4.0 & 640 & 2.0 & 2.0 & 302 & 1.0 & 1.0 & 0.48 \\
\hline Malta & 0.885 & 2304 & 9.6 & 18 & 4.2 & 1.9 & 6 & 1.4 & 0.4 & 0.33 \\
\hline Mauritius & 0.796 & 506 & 5.5 & 62 & 4.9 & 3.3 & 28 & 2.2 & 1.5 & 0.45 \\
\hline Netherlands & 0.934 & 4746 & 10.7 & 1418 & 8.5 & 4.4 & 257 & 1.5 & 0.7 & 0.18 \\
\hline New Zealand & 0.921 & 3554 & 9.3 & 264 & 5.7 & 3.4 & 58 & 1.2 & 0.7 & 0.21 \\
\hline Norway & 0.954 & 7464 & 10.0 & 362 & 6.9 & 3.7 & 68 & 1.3 & 0.7 & 0.19 \\
\hline Oman & 0.834 & 636 & 3.8 & 65 & 1.3 & 2.0 & 31 & 0.6 & 1.1 & 0.49 \\
\hline Philippines & 0.712 & 127 & 4.4 & 1372 & 1.3 & 1.6 & 673 & 0.6 & 0.8 & 0.48 \\
\hline Poland & 0.872 & 797 & 6.3 & 3203 & 8.6 & 4.8 & 1505 & 4.0 & 2.2 & 0.47 \\
\hline Portugal & 0.850 & 1722 & 9.0 & 817 & 8.2 & 4.3 & 269 & 2.7 & 1.4 & 0.33 \\
\hline Qatar & 0.848 & 2030 & 3.1 & 26 & 1.0 & 2.0 & 14 & 0.5 & 1.4 & 0.54 \\
\hline Russian Federation & 0.824 & 524 & 5.6 & 9340 & 6.6 & 4.0 & 5443 & 3.8 & 2.3 & 0.58 \\
\hline Serbia & 0.799 & 491 & 9.4 & 701 & 8.1 & 4.9 & 261 & 3.0 & 1.7 & 0.37 \\
\hline Singapore & 0.935 & 2280 & 4.3 & 199 & 3.5 & 1.9 & 85 & 1.5 & 0.8 & 0.43 \\
\hline Slovakia & 0.857 & 1108 & 6.9 & 541 & 10.1 & 6.0 & 224 & 4.2 & 2.5 & 0.42 \\
\hline Slovenia & 0.902 & 1772 & 8.5 & 135 & 6.7 & 3.5 & 47 & 2.3 & 1.1 & 0.34 \\
\hline South Africa & 0.705 & 471 & 8.2 & 1328 & 2.3 & 2.7 & 829 & 1.4 & 1.7 & 0.61 \\
\hline South Korea & 0.906 & 2013 & 7.4 & 1467 & 2.9 & 1.6 & 507 & 1.0 & 0.5 & 0.34 \\
\hline Spain & 0.893 & 2354 & 9.2 & 3843 & 8.6 & 4.0 & 969 & 2.2 & 1.0 & 0.26 \\
\hline Sweden & 0.937 & 5600 & 11.0 & 556 & 5.7 & 2.8 & 145 & 1.5 & 0.7 & 0.26 \\
\hline Switzerland & 0.946 & 9818 & 12.1 & 639 & 7.7 & 4.0 & 184 & 2.2 & 1.1 & 0.29 \\
\hline Thailand & 0.765 & 217 & 3.8 & 4169 & 6.1 & 3.8 & 2159 & 3.2 & 2.0 & 0.52 \\
\hline Trinidad and Tobago & 0.799 & 1146 & 6.0 & 42 & 3.1 & 2.2 & 20 & 1.5 & 1.1 & 0.48 \\
\hline Ukraine & 0.750 & 125 & 6.1 & 3358 & 7.8 & 4.4 & 2058 & 4.7 & 2.8 & 0.60 \\
\hline United Kingdom & 0.920 & 4356 & 9.9 & 5645 & 8.7 & 4.9 & 1443 & 2.2 & 1.1 & 0.25 \\
\hline United States of America & 0.920 & 9536 & 16.8 & 22715 & 7.1 & 4.2 & 3830 & 1.2 & 0.7 & 0.17 \\
\hline Uruguay & 0.808 & 1281 & 9.2 & 149 & 4.4 & 2.9 & 70 & 2.1 & 1.3 & 0.48 \\
\hline
\end{tabular}

3.3. Association between MIR and Parameters of the Development and Health Expenditures in the Selected Countries

We further examined the association of incidence and mortality CR with the HDI, the $\mathrm{CHE}$, and the CHE/GDP. The CR of incidence had a significant correlation with the HDI $(p<0.001$, Figure 1A), the CHE ( $p=0.005$, Figure 1C), and CHE/GDP $(p<0.001$, Figure 1E). The CR of mortality did not have a significant association with the HDI $(p=0.303$, Figure 1B), the CHE ( $p=0.997$, Figure 1D), and the CHE/GDP $(p=0.101$, Figure 1F). In addition, the results revealed a significant association of the MIRs with the HDI, the CHE per capita in USD, and the CHE/GDP with the MIR of lip and oral cancer (coefficient correlation $=-0.597, p<0.001$; coefficient correlation $=-0.652, p<0.001$; coefficient correlation $=-0.651, p<0.001$, respectively, Figure 2). 
(A)

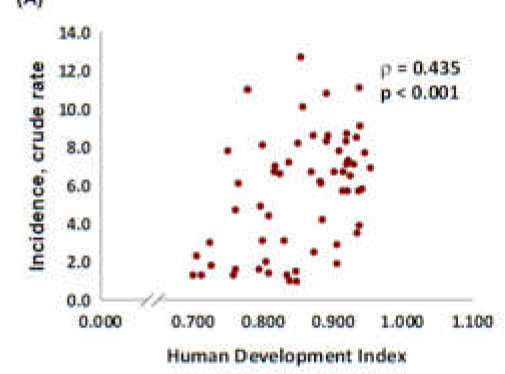

(C)
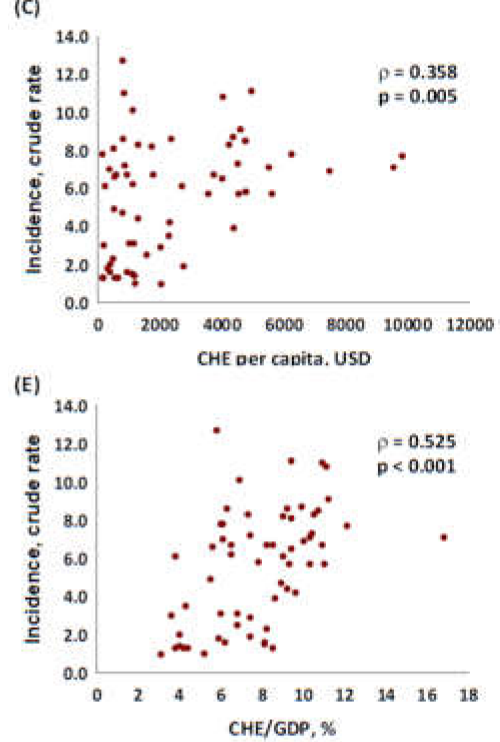

(B)

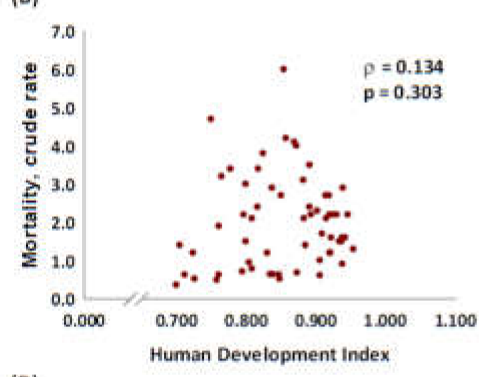

(D)

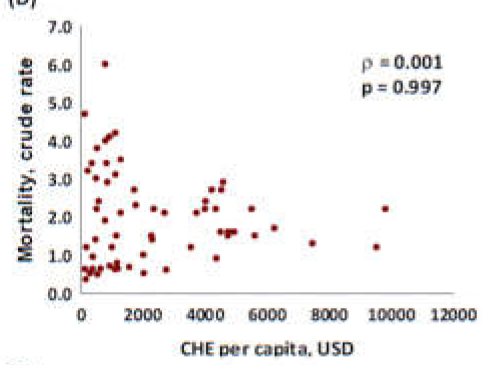

(F)

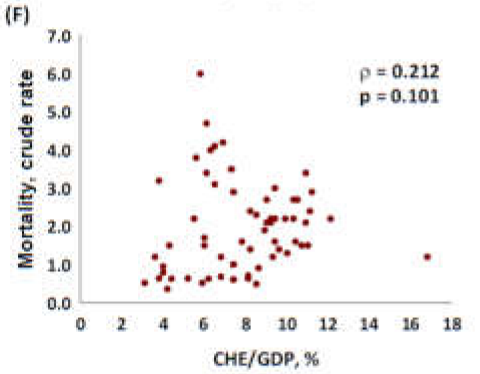

Figure 1. Association between HDI, CHE, and CRs of $(\mathbf{A}, \mathbf{C}, \mathbf{E})$ incidence, and $(\mathbf{B}, \mathbf{D}, \mathbf{F})$ mortality in lip and oral cancer.
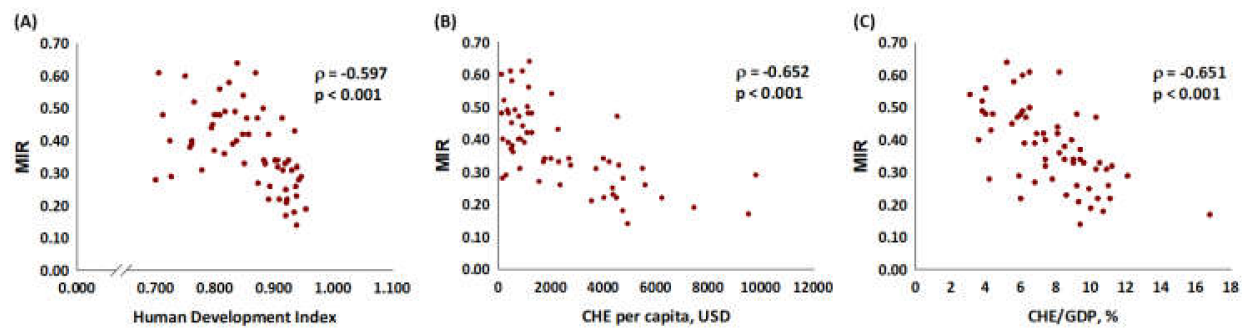

Figure 2. (A) HDI, (B) CHE per capita, and (C) CHE/GDP are significantly associated with the MIR for lip and oral cancer.

\section{Discussion}

In the present study, we analyzed the incidence and mortality of selected countries. The findings showed that Asia had the most cases and deaths among all countries. These results showed the correlation of the geographic distribution of betel chewing with high oral cancer incidence and mortality. In Asia, especially Southeast Asia, chewing betel quid that has various ingredients is a prevalent oral habit [5]. Betel quid has been considered a carcinogen by the International Agency for Research on Cancer (IARC) for several years [27]. Previous results have shown that betel quid chewing has a significant negative effect on oral cancer and precancer [28]. Longer duration and higher frequency of betel quid chewing have been found to increase the risk of oral cancer [29].

Our findings showed that countries with higher HDIs and CHEs had higher incidence rates (Figure 1). This result supports the findings of previous studies that indicated the cancer incidence burden was greater in countries with higher HDIs [30]. This finding might have been because more developed countries have more comprehensive medical facilities, and patient education. 
Some novel methods, such as Toluidine blue staining, brush biopsy, chemiluminescence, and tissue fluorescence spectroscopy screening, aid in the early diagnosis of oral cancer [7]. The early detection of oral cancer and public awareness of oral cancer screening are some of the most efficient ways to reduce mortality rates and contribute to better outcomes [31]. Previous results also showed that socioeconomic disparities influence oral cancer screening [8], which affects the severity at diagnosis and prognosis [32].

However, in comparing HDI, CHE, and CHE/GDP with MIR, we discovered that more developed countries had lower MIRs (Figure 2) with significant correlations. A previous study showed that MIR was a valid proxy for five-year relative survival [33], which supported that more developed countries have longer survival rates. A previous retrospective study showed that in recent decades, improved operative techniques, advanced preoperative image assessment, and efficient radiotherapy enabled a substantial increase in oral cavity squamous cell carcinoma survival rates [34]. In addition, new options, such as immunotherapy and target therapy, have become increasingly popular in treating oral cancer in advanced stages [9]. Due to the deepened understanding of the oncogenic and epigenetic pathways of oral cancer, more biomarkers for identifying invasive and metastatic potential tumors have been discovered. Moreover, based on genetic findings, there have been advances in precision therapy [35]. Thus, previous findings indicated that countries with higher HDIs and CHEs have higher early detection rates and more effective treatment, which leads to higher incidence rates and lower MIRs, which is compatible with our results.

A previous study showed that because the MIR lacked comprehensive follow-ups, it could not replace cancer survival rates or prognostic data on long-term follow-ups or cohort studies [36]. However, other studies have shown that the MIR is still a simple and efficient method for identifying cancer control [33]. The MIR has also been shown to be a suitable method for examining cancer screening and treatment programs worldwide [22].

The present study has the following limitations. First, some important risk factors for lip and oral cancer, such as alcohol consumption, smoking, betel chewing, and other oral behaviors among different countries, were not recorded or analyzed. These risk factors may play important roles in explaining and determining incidence and mortality rates among countries and regions. Second, the feasibility of using WHO rankings and CHE/GDP to represent healthcare disparities among countries was not confirmed to apply to different cancers. The data reported by GLOBOCAN were based on estimates in some countries. National healthcare systems, disparities in the access to cancer care, and insurance coverage were not analyzed. Despite these limitations, the findings showed that the MIR appears to provide more accessible data compared with long-term follow-up survival surveys.

\section{Conclusions}

The MIR for lip and oral cancer is significantly associated with the HDI, the CHE per capita, and the CHE/GDP. Countries with higher HDIs, higher CHE per capita, and higher $\mathrm{CHE} / \mathrm{GDP}$ tend to have longer survival rates.

Author Contributions: Conceptualization, C.-J.C.; formal analysis, W.-W.S. and Y.-C.H.; methodology, Y.-C.H. and Y.-C.C. (Ying-Ching Chen); supervision, C.-J.C. and W.-W.S.; investigation, C.D., Y.-C.H., and Y.-C.C. (Yu-Chi Chao); writing-original draft preparation, Y.-C.H., C.D., Y.-C.C. (YingChing Chen) and Y.-C.C. (Yu-Chi Chao); writing-review and editing, C.-J.C. and W.-W.S. All authors have read and agreed to the published version of the manuscript.

Funding: This research received no external funding.

Institutional Review Board Statement: Not applicable.

Informed Consent Statement: Not applicable. 
Data Availability Statement: The datasets used and/or analyzed during the current study are publicly available in the Global Cancer Observatory (GLOBOCAN) database (https:/ / gco.iarc.fr/today/, accessed date: 11 October 2020), United Nations Development Program/Human Development Report Office (http:/ /hdr.undp.org/en, accessed date: 11 October 2020) and World Health Statistics database (https:/ / www.who.int/gho/publications/world_health_statistics/en/, accessed date: 11 October 2020).

Acknowledgments: Not applicable.

Conflicts of Interest: The authors declare no conflict of interest.

\section{References}

1. Siegel, R.L.; Miller, K.D.; Jemal, A. Cancer statistics, 2020. Cancer Rehabil. 2020, 70, 7-30. [CrossRef] [PubMed]

2. Ghantous, Y.; Abu Elnaaj, I. Global incidence and risk factors of oral cancer. Harefuah 2017, 156, 645-649. [PubMed]

3. Dhanuthai, K.; Rojanawatsirivej, S.; Thosaporn, W.; Kintarak, S.; Subarnbhesaj, A.; Darling, M.; Kryshtalskyj, E.; Chiang, C.-P.; Shin, H.-I.; Choi, S.-Y.; et al. Oral cancer: A multicenter study. Med. Oral Patol. Oral Cir. Bucal 2018, 23, e23-e29. [CrossRef] [PubMed]

4. LeHew, C.W.; Weatherspoon, D.J.; Peterson, C.E.; Goben, A.; Reitmajer, K.; Sroussi, H.; Kaste, L.M. The Health System and Policy Implications of Changing Epidemiology for Oral Cavity and Oropharyngeal Cancers in the United States From 1995 to 2016 Epidemiol. Rev. 2017, 39, 132-147. [CrossRef]

5. Kumar, M.; Nanavati, R.; Modi, T.G.; Dobariya, C. Oral cancer: Etiology and risk factors: A review. J. Cancer Res. Ther. 2016, 12, 458-463. [CrossRef]

6. Yanik, E.L.; Katki, H.A.; Silverberg, M.J.; Manos, M.M.; Engels, E.A.; Chaturvedi, A.K. Leukoplakia, Oral Cavity Cancer Risk, and Cancer Survival in the U.S. Elderly. Cancer Prev. Res. (Phila) 2015, 8, 857-863. [CrossRef] [PubMed]

7. Jitender, S.; Warnakulasuriya, S. Screening for oral cancer. J. Exp. Ther. Oncol. 2016, 11, 303-307.

8. Kravietz, A.; Angara, P.; Le, M.; Sargi, Z. Disparities in Screening for Head and Neck Cancer: Evidence from the NHANES, 2011-2014. Otolaryngol. Head Neck Surg. 2018, 159, 683-691. [CrossRef] [PubMed]

9. Kaidar-Person, O.; Gil, Z.; Billan, S. Precision medicine in head and neck cancer. Drug Resist. Updat. 2018, 40, 13-16. [CrossRef]

10. Cheraghlou, S.; Schettino, A.; Zogg, C.K.; Jodson, B.L. Changing prognosis of oral cancer: An analysis of survival and treatment between 1973 and 2014. Laryngoscope 2018, 128, 2762-2769. [CrossRef]

11. Shah, J.P.; Gil, Z. Current concepts in management of oral cancer-Surgery. Oral Oncol. 2009, 45, 394-401. [CrossRef]

12. D'Cruz, A.K.; Vaish, R.; Dhar, H. Oral cancers: Current status. Oral Oncol. 2018, 87, 64-69. [CrossRef] [PubMed]

13. Yu, A.J.; Choi, J.S.; Swanson, M.S.; Kokot, N.C.; Brown, T.N.; Yan, G.; Sinha, U.K. Association of Race/Ethnicity, Stage, and Survival in Oral Cavity Squamous Cell Carcinoma: A SEER Study. OTO Open 2019, 3, 2473974X19891126. [CrossRef]

14. Farhood, Z.; Simpson, M.; Ward, G.M.; Walker, R.J.; Osazuwa-Peters, N. Does anatomic subsite influence oral cavity cancer mortality? A SEER database analysis. Laryngoscope 2019, 129, 1400-1406. [CrossRef] [PubMed]

15. Gaubatz, M.E.; Bukatko, A.R.; Simpson, M.C.; Polednik, K.M.; Boakye, E.A.; Varvares, M.A.; Osazuwa-Peters, N. Racial and socioeconomic disparities associated with 90-day mortality among patients with head and neck cancer in the United States. Oral Oncol. 2019, 89, 95-101. [CrossRef]

16. Agarwal, P.; Agrawal, R.R.; Jones, E.A.; Devaiah, A.K. Social determinants of health and oral cavity cancer treatment and survival: A competing risk analysis. Laryngoscope 2019. [CrossRef]

17. Inverso, G.; Mahal, B.A.; Aizer, A.A.; Donoff, R.B.; Chuang, S.-K. Health Insurance Affects Head and Neck Cancer Treatment Patterns and Outcomes. J. Oral Maxillofac. Surg. 2016, 74, 1241-1247. [CrossRef] [PubMed]

18. Ghantous, Y.; Yaffi, V.; Abu-Elnaaj, I. Oral cavity cancer: Epidemiology and early diagnosis. Refuat Hapeh Vehashinayim (1993) 2015, 32, 55-63, 71 .

19. Akinkugbe, A.A.; Garcia, D.T.; Brickhouse, T.H.; Mosavel, M. Lifestyle risk factor related disparities in oral cancer examination in the U.S: A population-based cross-sectional study. BMC Public Health 2020, 20, 153. [CrossRef]

20. Choi, E.; Lee, S.; Nhung, B.C.; Suh, M.; Park, B.; Jun, J.K.; Choi, K.S. Cancer mortality-to-incidence ratio as an indicator of cancer management outcomes in Organization for Economic Cooperation and Development countries. Epidemiol. Health 2017, 39, e2017006. [CrossRef]

21. Eberth, J.M.; Zahnd, W.E.; Adams, S.A.; Friedman, D.B.; Wheeler, S.B.; Hébert, J.R. Mortality-to-incidence ratios by US Congressional District: Implications for epidemiologic, dissemination and implementation research, and public health policy. Prev. Med. 2019, 129, 105849. [CrossRef] [PubMed]

22. Sunkara, V.; Hébert, J.R. The colorectal cancer mortality-to-incidence ratio as an indicator of global cancer screening and care. Cancer 2015, 121, 1563-1569. [CrossRef] [PubMed]

23. Chen, S.L.; Wang, S.-C.; Ho, C.-J.; Kao, Y.-L.; Hsieh, T.-Y.; Chen, W.-J.; Chen, C.-J.; Wu, P.-R.; Ko, J.-L.; Lee, H.; et al. Prostate Cancer Mortality-To-Incidence Ratios Are Associated with Cancer Care Disparities in 35 Countries. Sci. Rep. 2017, 7, 40003. [CrossRef]

24. Sung, W.W.; Wang, S.-C.; Hsieh, T.-Y.; Ho, C.-J.; Huang, C.-Y.; Kao, Y.-L.; Chen, W.-J.; Chen, S.-L. Favorable mortality-to-incidence ratios of kidney Cancer are associated with advanced health care systems. BMC Cancer 2018, 18, 792. [CrossRef] [PubMed] 
25. Wang, S.C.; Sung, W.-W.; Kao, Y.-L.; Hsieh, T.-Y.; Chen, W.-J.; Chen, S.-L.; Chang, H.-R. The gender difference and mortality-toincidence ratio relate to health care disparities in bladder cancer: National estimates from 33 countries. Sci. Rep. 2017, 7, 4360. [CrossRef]

26. Huang, C.Y.; Au, K.-K.; Chen, S.-L.; Wang, S.-C.; Liao, C.-Y.; Hsu, H.-H.; Sung, W.-W.; Wang, Y.-C. Unfavorable Mortality-ToIncidence Ratio of Lung Cancer Is Associated with Health Care Disparity. Int. J. Environ. Res. Public Health 2018, 15, 2889. [CrossRef]

27. International Agency for Research on Cancer. Personal habits and indoor combustions. Volume 100 E. A review of human carcinogens. IARC Monogr. Eval. Carcinog. Risks Hum. 2012, 100 Pt E, 1-538.

28. Song, H.; Wan, Y.; Xu, Y.Y. Betel quid chewing without tobacco: A meta-analysis of carcinogenic and precarcinogenic effects. Asia Pac. J. Public Health 2015, 27, Np47-Np57. [CrossRef] [PubMed]

29. Guha, N.; Warnakulasuriya, S.; Vlaanderen, J.; Straif, K. Betel quid chewing and the risk of oral and oropharyngeal cancers: A meta-analysis with implications for cancer control. Int. J. Cancer 2014, 135, 1433-1443. [CrossRef]

30. Fidler, M.M.; Bray, F.; Soerjomataram, I. The global cancer burden and human development: A review. Scand. J. Public Health 2018, 46, 27-36. [CrossRef]

31. Mehrotra, R.; Gupta, D.K. Exciting new advances in oral cancer diagnosis: Avenues to early detection. Head Neck Oncol. 2011, 3, 33. [CrossRef] [PubMed]

32. Molina, M.A.; Cheung, M.C.; Perez, E.A.; Byrne, M.M.; Franceschi, D.; Moffat, F.L.; Livingstone, A.S.; Goodwin, W.J.; Gutierrez, J.C.; Koniaris, L.G. African American and poor patients have a dramatically worse prognosis for head and neck cancer: An examination of 20,915 patients. Cancer 2008, 113, 2797-2806. [CrossRef]

33. Asadzadeh Vostakolaei, F.; Karim-Kos, H.E.; Janssen-Heijnen, M.L.G.; Visser, O.; Verbeek, A.L.M.; Kiemeney, L. The validity of the mortality to incidence ratio as a proxy for site-specific cancer survival. Eur. J. Public Health 2011, 21, 573-577. [CrossRef] [PubMed]

34. Amit, M.; Yen, T.-C.; Liao, C.-T.; Chaturvedi, P.; Agarwal, J.P.; Kowalski, L.P.; Ebrahimi, A.; Clark, J.R.; Kreppel, M.; Zöller, J.; et al. Improvement in survival of patients with oral cavity squamous cell carcinoma: An international collaborative study. Cancer 2013, 119, 4242-4248. [CrossRef]

35. Li, C.C.; Shen, Z.; Bavarian, R.; Yang, F.; Bhattacharya, A. Oral Cancer: Genetics and the Role of Precision Medicine. Dent. Clin. North. Am. 2018, 62, 29-46. [CrossRef]

36. Ellis, L.; Belot, A.; Rachet, B.; Coleman, M.P. The Mortality-to-Incidence Ratio Is Not a Valid Proxy for Cancer Survival. J. Glob. Oncol. 2019, 5, 1-9. [CrossRef] [PubMed] 